\title{
Determination of Optimized Growth Medium and Cryoprotective Additives to Enhance the Growth and Survival of Lactobacillus salivarius $\overline{\text { [S }}$
}

\author{
Soyoung Yeo ${ }^{1}$, Hee Sung Shin ${ }^{2}$, Hye Won Lee ${ }^{2}$, Doseon Hong' ${ }^{2}$ Hyunjoon Park ${ }^{3}$, Wilhelm Holzapfel ${ }^{4}$, \\ Eun Bae Kim ${ }^{5}$, and Chul Sung Huh, ${ }^{1,2 *}$ \\ ${ }^{1}$ Research Institute of Eco-friendly Livestock Science, Institute of Green-Bio Science and Technology, Seoul National University, Pyeongchang \\ 25354, Republic of Korea \\ ${ }^{2}$ Graduate School of International Agricultural Technology, Seoul National University, Pyeongchang 25354, Republic of Korea \\ ${ }^{3}$ Department of Life Sciences, Handong Global University, Pohang 37554, Republic of Korea \\ ${ }^{4}$ Advanced Green Energy and Environment Institute (AGEE), Handong Global University, Pohang 37554, Republic of Korea \\ ${ }^{5}$ Department of Animal Life Science, College of Animal Life Sciences, Kangwon National University, Chuncheon 24341, Republic of Korea
}

Received: January 28, 2018

Revised: March 9, 2018

Accepted: March 12, 2018

First published online

March 16, 2018

*Corresponding author

Phone: +82-10-9216-9601;

Fax: +82-33-339-5717;

E-mail: chulsunghuh@gmail.com

S upplementary data for this paper are available on-line only at http://jmb.or.kr.

pISSN 1017-7825, eISSN 1738-8872

Copyright(C) 2018 by

The Korean Society for Microbiology and Biotechnology
The beneficial effects of lactic acid bacteria (LAB) have been intensively investigated in recent decades with special focus on modulation of the host intestinal microbiota. Numerous discoveries of effective probiotics are driven by a significantly increasing demand for dietary supplements. Consequently, technological advances in the large-scale production and lyophilization are needed by probiotic-related industries for producing probiotic LAB for commercial use. Our study had a dual objective, to determine the optimum growth medium composition and to investigate appropriate cryoprotective additives (CPAs) for Lactobacillus salivarius, and compare its responses with other Lactobacillus species. The one-factor-at-a-time method and central composite design were applied to determine the optimal medium composition for L. salivarius cultivation. The following composition of the medium was established (per liter): $21.64 \mathrm{~g}$ maltose, $85 \mathrm{~g}$ yeast extract, $1.21 \mathrm{ml}$ Tween $80,6 \mathrm{~g}$ sodium acetate, $0.2 \mathrm{~g} \mathrm{MgSO}_{4} \cdot 7 \mathrm{H}_{2} \mathrm{O}, 0.02 \mathrm{~g} \mathrm{MnSO}_{4} \cdot \mathrm{H}_{2} \mathrm{O}, 1 \mathrm{~g} \mathrm{~K}_{2} \mathrm{HPO}_{4}, 1.5 \mathrm{~g} \mathrm{KH}_{2} \mathrm{PO}_{4}, 0.01 \mathrm{~g} \mathrm{FeSO}_{4} \cdot 7 \mathrm{H}_{2} \mathrm{O}$, and $1 \mathrm{~g}$ sodium citrate. A cryoprotective additive combination comprising $10 \%(\mathrm{w} / \mathrm{v})$ skim milk and $10 \%(\mathrm{w} / \mathrm{v})$ sucrose supplemented with $2.5 \%(\mathrm{w} / \mathrm{v})$ sodium glutamate was selected for L. salivarius, and its effectiveness was confirmed using culture-independent methods in the freeze-dried cells of the Lactobacillus strains. In conclusion, the optimized medium enhanced the species-specific cultivation of L. salivarius. On the other hand, the cryoprotective effects of the selected CPA mixture may also be dependent on the bacterial strain. This study highlights the necessity for precise and advanced processing techniques for large-scale production of probiotics in the food and feed industries.

Keywords: Lactic acid bacteria, cultivation, growth medium, freeze-drying, viability, cultureindependent method

\section{Introduction}

The lactic acid bacteria (LAB) are a group of microorganisms generally regarded as safe for the host [1]. With an estimated $>200$ species presently, the genus Lactobacillus is the largest representative of the LAB, within Phylum Firmicutes, whereas Bifidobacterium species, frequently considered as LAB, phylogenetically belong to the Actinobacteria [2]. Probiotic LAB have become a focus of the feed, food, and pharmaceutical industries owing to their 
ability to modulate the microbiota in the host gastrointestinal tract, conferring beneficial effects in the host [3-5]. Recent studies have shown that modulation of the gut microbiota is a new beneficial target related to host health by affecting its immune system [6,7]. Even though probiotic LAB have long been consumed in fermented foods and beverages by the host, the consumption of probiotics is increasing as a result of dietary supplements, with an expected compound annual growth rate of $7.6 \%$ over the next 9 years [8]. This increase in demand has led to recent advances in technologies for the large-scale industrial production and lyophilization of probiotics, resulting in improvements in delivery systems, such as the production of freeze-dried probiotic tablets for long-term storage.

Lactobacillus salivarius is commonly found naturally in the mammalian gastrointestinal tract and has been reported to possess certain abilities such as enhancement of the immune system, attenuation of gut inflammation, and modulation of the gut microbiota [9-11]. In particular, L. salivarius has gained attention as one of the effective antimicrobial probiotic species of $\mathrm{LAB}$ owing to its ability to produce unmodified bacteriocins of subclasses IIa, IIb, and IId [10]. The promising probiotic strain mainly used in this study, L. salivarius strain W13, was selected among 284 representative isolates from the intestine of a weaning piglet. The strain has been reported to have antimicrobial activity against enterotoxigenic Escherichia coli K88 and Salmonella enterica serovar Typhimurium strains in a previous study. Furthermore, the genome of the strain contains three genes for bile hydrolysis that may assign tolerance to a bile-rich environment such as gastrointestinal tract, which might be employed as feed additives for piglets [12]. The MRS (deMan, Rogosa, and Sharp) medium introduced by de Man et al. [13] has been widely used as a commercial medium for Lactobacillus species from various sources because it contains essential ingredients (polysorbate, acetate, magnesium, and manganese) as well as growth-inhibiting reagents to suppress the growth of unfavorable bacteria. However, MRS medium is not sufficient to maximize the growth of some lactobacilli, because the nutritional requirements differ depending on the Lactobacillus species or strain [14]. Most of the research studies for culture medium optimization have been focused on a certain strain, such as L. rhamnosus [15, 17], L. plantarum [14, 40], L. fermentum [41, 44], and L. salivarius [18, 36], with the "one-factor-at-a-time" method, the Plackett-Burman design, and the response surface methodology (RSM). However, there are few cases considered at the species level.

Cryoprotective additives (CPAs) are used for preserving bacterial viability during lyophilization. The rates of suppressing ice crystal formation depend on the content and chemical characteristics of the contained CPAs as well as the time required for ice nucleation and formation in the freeze-drying process [19]. The cryopreservation of CPAs was determined on the basis of bacterial viability, which has been traditionally quantified using culture-dependent methods [20, 21]. However, this technique not only requires time-consuming incubation but is suitable for detecting only stress-resilient cells on agar-based medium, and does not detect dormant cells that are metabolically inactive but ultimately cultivable $[22,23]$. Therefore, alternative methods are needed for defining the bacterial viability state in lyophilized products. In this study, we employed a dualstaining technique with fluorescent dyes (SYTO9 and propidium iodide (PI)) using flow cytometry to discriminate between viable (active or inactive) and dead cells for the precise assessment of the cryoprotective effects on the viability of freeze-dried cells [24, 25]. In addition, the effect of CPAs on the viability of L. salivarius was confirmed using imaging (fluorescence in situ hybridization) as one of the culture-independent techniques. Furthermore, bacterial metabolic activity after freeze-drying was also examined by detecting the adenosine triphosphate (ATP) concentration.

This study had a dual objective with regard to L. salivarius strains: to optimize the cultivation conditions and to investigate CPA candidates for large-scale production. The determined cultivation conditions and CPA mixture were assessed across Lactobacillus species using 12 strains of L. salivarius as well as commercial Lactobacillus species.

\section{Materials and Methods}

\section{Bacterial Strains and Culture Conditions}

The origins and sources of Lactobacillus strains used in this study are provided in Table S1. Lactobacillus salivarius strain W13, deposited as strain KLW001, was mainly used to establish conditions for cultivation and lyophilization. The LAB strains used for comparison included L. salivarius strains W90, LS1, LS3, LS4, LS6, and LS8, L. rhamnosus GG (ATCC 53103), L. brevis subsp. coagulans Labre, L. plantarum 299v, L. acidophilus NCFM, and L.fermentum ME-3, which was kindly provided by Professor Marika Mikelsaar (Department of Microbiology, University of Tartu, Estonia). Bacterial pure cultures were maintained in MRS broth (Difco, USA) and stored at $-80^{\circ} \mathrm{C}$ in MRS broth with $20 \%$ $(\mathrm{v} / \mathrm{v})$ sterile glycerol. All strains used in this study were incubated at $37^{\circ} \mathrm{C}$ and subcultured at least twice before use.

The base medium consisted of the following ingredients: $40 \mathrm{~g} / 1$ dextrose, $20 \mathrm{~g} / 1$ yeast extract, $6 \mathrm{~g} / 1$ sodium acetate anhydrous, $0.2 \mathrm{~g} / 1$ magnesium sulfate heptahydrate, $0.02 \mathrm{~g} / 1$ manganese 
sulfate hydrate, $1 \mathrm{~g} / 1$ dipotassium phosphate, $1.5 \mathrm{~g} / 1$ monopotassium phosphate, $0.01 \mathrm{~g} / 1$ ferrous sulfate heptahydrate, $1 \mathrm{~g} / 1$ sodium citrate monobasic, and $1 \mathrm{ml} / 1$ Tween 80 . The initial $\mathrm{pH}$ was adjusted to $6.5 \pm 0.1$ with $3.0 \mathrm{~mol} / 1 \mathrm{NaOH}$ solution. All chemicals were purchased either from Sigma-Aldrich (USA) or Difco (USA). MRS medium was used as a control for comparison of the growth rates. All media were inoculated with $1 \%(\mathrm{v} / \mathrm{v})$ bacterial inoculum in $15-\mathrm{ml}$ conical tubes (final volume $10 \mathrm{ml}$ ), and incubated at $37^{\circ} \mathrm{C}$ for $18 \mathrm{~h}$. The bacterial culture was harvested and serially diluted 10-fold in sterile saline solution, and then plated onto MRS agar plates in triplicate. Viable cell numbers (CFU/ml) were determined at the stationary phase (18 $\mathrm{h}$ incubation).

\section{Determination of Medium Compositions}

Initial screening of nutrients. To identify the L. salivariuspreferred carbohydrate and nitrogen sources, and growth factors, the effects of each source were screened at concentrations of $4 \%$ $(\mathrm{w} / \mathrm{v}), 2 \%(\mathrm{w} / \mathrm{v})$, and $0.1 \%(\mathrm{v} / \mathrm{v})$ in the base medium as a replacement of dextrose, yeast extract, and Tween 80 , respectively. The other components were maintained at a fixed level. All experiments were performed using the one-factor-at-a-time methodology [26]. The selected nutrients were adopted to search for the optimal combinations for the central composite design.

Response surface methodology and statistical analysis. The experimental design was carried out using Design-Expert 10 software ver. 10 (Stat-Ease Inc., USA). A central composite design was applied to identify the interactive effects of four selected factors (carbon, nitrogen, growth factors, and initial $\mathrm{pH}$ ) on both viable cell numbers $\left(Y_{1}, \log \mathrm{CFU} / \mathrm{ml}\right)$ at the stationary phase and the growth rate $\left(Y_{2}, \mathrm{~min}\right)$ at the exponential phase. The growth rate was calculated according to the time when the optical density at $600 \mathrm{~nm}$ reached 2.0. The experimental design is described in Table 1. Analysis of variance (ANOVA) was performed to determine the post prediction and reproducibility of the estimated combinations.

Screening of the nitrogen source concentration. L. salivarius strain W13 was inoculated at $1 \%(\mathrm{v} / \mathrm{v})$ into each medium containing different concentrations of yeast extract ranging from $2 \%(\mathrm{w} / \mathrm{v})$ to $9.5 \%(\mathrm{w} / \mathrm{v})$. The other components were maintained at a fixed level. The number of viable cells was counted on MRS agar plates at the stationary phase.

Up-scale cultivation. Lactobacillus strains were cultured in a 5-L

Table 1. Independent variables and range of levels.

\begin{tabular}{lcccccc}
\hline \multirow{2}{*}{\multicolumn{1}{c}{ Variables }} & & \multicolumn{6}{c}{$\begin{array}{c}\text { Actual values of coded and } \\
\text { actual levels }\end{array}$} \\
\cline { 3 - 8 } & Symbol & \multicolumn{6}{c}{$-\alpha$} & -1 & 0 & +1 & $+\alpha$ \\
\hline Maltose $(\%, \mathrm{w} / \mathrm{v})$ & $X_{1}$ & 2.0 & 3.0 & 4.0 & 5.0 & 6.0 \\
Yeast extract (\%, w/v) & $X_{2}$ & 1.0 & 1.5 & 2.0 & 2.5 & 3.0 \\
Tween $80(\%, \mathrm{v} / \mathrm{v})$ & $X_{3}$ & 0 & 0.05 & 0.1 & 0.15 & 0.2 \\
$\mathrm{pH}$ & $X_{4}$ & 5.5 & 6.0 & 6.5 & 7.0 & 7.5 \\
\hline
\end{tabular}

fermenter (Ecell 3000; Ecell, Korea) for large-scale production. The actual working volume was $3.5 \mathrm{~L}$, and all instruments and media were thoroughly sterilized before use. During the cultivation, nitrogen gas was not sparged into the culture, and the impeller speed was maintained at $180 \mathrm{rpm}$. The culture $\mathrm{pH}$ was automatically controlled at 7.0 using either $3 \mathrm{~mol} / 1 \mathrm{HCl}$ or $3 \mathrm{~mol} / \mathrm{l} \mathrm{NaOH}$, and the temperature was consistently sustained at $37^{\circ} \mathrm{C}$ by a bath circulator (MaXircu CR-8; DAIHAN Scientific, Korea). Each strain was inoculated as a $1 \%(\mathrm{v} / \mathrm{v})$ inoculum and incubated for $18 \mathrm{~h}$. The bacterial cells were harvested for the enumeration of viable cells and freeze-drying.

\section{Determination of Cryoprotective Additives}

Freeze-drying and recovery of lyophilized cells. Bacterial cells were centrifuged at 7,000 $\times g$ for $15 \mathrm{~min}$ at $4^{\circ} \mathrm{C}$ (Centrifuge Supra 22K; Hanil Science, Korea). The harvested pellets were washed twice in $0.85 \%(\mathrm{w} / \mathrm{v}) \mathrm{NaCl}$ solution, and then resuspended with each cryoprotective agent to up to 50-times the original concentration. Each suspension was frozen at $-80^{\circ} \mathrm{C}$ in $100-\mathrm{mm}$ petri dishes. After $24 \mathrm{~h}$, the dishes were transferred to a freeze-dryer (MCFD8518; IlShinBioBase, Korea) and the condenser temperature was maintained at $-85^{\circ} \mathrm{C}$ for $24 \mathrm{~h}$. The freeze-dried bacterial powders were placed in conical tubes and stored at $-80^{\circ} \mathrm{C}$ for up to 2 weeks. Each $0.1 \mathrm{~g}$ of lyophilized cells was immediately suspended in $1 \mathrm{ml}$ of $0.85 \%(\mathrm{w} / \mathrm{v}) \mathrm{NaCl}$ solution for the detection of viability and metabolic activity. The bacterial survival ratio (\%) was calculated as the cell count before and after freeze-drying, using the plate counting method. (Information on the CPAs is provided in Table 4.)

Fluorescence-based assay. The LIVE/DEAD BacLight Bacterial Viability and Counting kit (Molecular Probes, Inc., USA) was used for dual-staining of nucleic acids in the freeze-dried bacteria. Briefly, $10 \mu \mathrm{l}$ of the bacterial suspension was added to $987 \mu \mathrm{l}$ of $0.85 \%(\mathrm{w} / \mathrm{v}) \mathrm{NaCl}$ solution along with $3.0 \mu \mathrm{l}$ of a SYTO9/PI mixture, and this suspension was incubated at room temperature in the dark for $15 \mathrm{~min}$. For fluorescence microscopy, $5 \mu \mathrm{l}$ of the stained suspension and $2 \mu \mathrm{l}$ of the BacLight mounting oil were dropped on a slide glass and covered with a coverslip. Each sample was observed under the Axio Imager.A2 microscope with HBO 100 illuminator (Carl Zeiss, Germany) and analyzed using ZEN 2012 software (Carl Zeiss, Germany). For the flow cytometry assay, $990 \mu \mathrm{l}$ of the stained suspension and $10 \mu \mathrm{l}$ of the presonicated microsphere standard were transferred to a flow cytometry tube (total volume, $1 \mathrm{ml}$ ). The density of the $6.0-\mu \mathrm{m}$ diameter microsphere standard was consistently applied at $1.0 \times$ $10^{6}$ beads $/ \mathrm{ml}$ for quantification of the bacterial cells. This assay was carried out according to the manufacturer's instructions with slight modifications. Fluorescence was detected in triplicate using the FACSCanto II (Becton-Dickinson, Inc., USA) equipped with $488 \mathrm{~nm}$ blue laser excitation, and the data were analyzed using BD FACSDiva software (Becton-Dickinson, USA). An unstained control and each single-color control were employed for background control and compensation, respectively. The total number of events was 10,000, and the detected dot plots were gated and 
defined in FSC (Forward-scatter), SSC (Side-scatter), SYTO9 (Ex $x_{\max }$ $\left.485 \mathrm{~nm}, \mathrm{Em}_{\max } 498 \mathrm{~nm}\right), \mathrm{PI}\left(\mathrm{Ex}_{\max } 533 \mathrm{~nm}, \mathrm{Em}_{\max } 617 \mathrm{~nm}\right)$, and bead populations on a logarithmic scale. The number of live and dead bacterial cells was calculated as follows:

Stained bacteria $/ \mathrm{ml}=[$ (number of events in a stained region $) \times$ (dilution factors)]/(number of events in a bead region) $\times 10^{-6}$

ATP activity assay. Bacterial ATP was measured using the BacTiter-Glo Microbial Cell Viability assay kit (Promega, USA), and the detected luminescence (RLU) was calculated according to the signal-to-noise ( $\mathrm{S}: \mathrm{N})$ ratio [27] as follows:

$\mathrm{S}: \mathrm{N}=$ (mean of signal - mean of background)/standard deviation of background

The bacterial suspension was added immediately after freezedrying to an equal volume of BacTiter-Glo reagent, which included $\mathrm{Mg}^{2+}$, luciferin, and luciferase. The luminescence signal was collected using a SpectraMax M3 (Molecular Devices, USA) within $5 \mathrm{~min}$. This experiment was conducted according to the manufacturer's instructions.

\section{Statistical Analysis}

GraphPad Prism software ver. 6.05 (GraphPad Software, Inc., USA) was used to evaluate differences in discrete variables between the groups (Student's $t$-test). The statistical significance of the central composite design model was analyzed by ANOVA using Design-Expert ver. 10 software.

\section{Accession Numbers}

The nucleotide sequences of the 16S rRNA genes have been deposited at the NCBI GenBank database under the accession numbers LXZG00000000.1, LXZF00000000.1, and KX266895KX266899 for L. salivarius strains W13 (deposited name: strain KLW001) and W90 (KLW002), and L. salivarius strains LS1, LS3, LS4, LS6, and LS8, respectively.

\section{Results}

\section{Determination and Validation of the Optimized Culture Medium}

Selection of single sources. The influence of particular ingredients on the growth of L. salivarius strain W13 was determined by the addition of eight different carbon and nitrogen sources, and growth factors, to the base medium (Table 2). When compared with the growth in MRS medium, all of the tested carbon sources increased viable cell numbers $(\mathrm{CFU} / \mathrm{ml})$ at the stationary phase, except for the polysaccharides (dextrin and soluble starch). Maltose was selected as the optimal carbon source because it significantly enhanced growth, showing the highest numbers with $5.2 \times 10^{8} \mathrm{CFU} / \mathrm{ml}$. Most of the nitrogen sources and growth factors tested did not enhance bacterial growth, with the exception of yeast extract and Tween 80 . These two ingredients increased cell numbers 1.14-fold compared with MRS medium, and thus were selected as a nitrogen source and growth factor in subsequent analyses.

Effects of selected factors with central composite design. Experiments were performed according to the treatment combinations described in Table 3. The optimization was derived from two responses in this study. By fitting the experimental responses with the least-squares method, two second-order polynomial regression models were obtained

Table 2. Influence of various carbon, nitrogen, and growth factor sources on the growth of Lactobacillus salivarius W13.

\begin{tabular}{cccccc}
\hline Carbon & $N / N_{\text {MRS }} \pm \mathrm{SD}^{a}$ & Nitrogen & $N / N_{\text {MRS }} \pm \mathrm{SD}$ & Growth factors & $N / N_{\text {MRS }} \pm \mathrm{SD}$ \\
\hline GAL & $1.65 \pm 0.58$ & SP & $0.28 \pm 0.01^{*}$ & FA & $0.03 \pm 0.01^{*}$ \\
FRU & $1.07 \pm 0.15$ & PP & $0.80 \pm 0.12^{*}$ & GA & $0.01 \pm 0.00^{*}$ \\
SUC & $2.02 \pm 0.17^{*}$ & BE & $0.35 \pm 0.01^{*}$ & HIS & $0.00 \pm 0.00^{*}$ \\
LAC & $1.79 \pm 0.46^{*}$ & TRY & $0.40 \pm 0.04^{*}$ & LYS & $0.00 \pm 0.00^{*}$ \\
MAL & $2.47 \pm 0.09^{*}$ & CAS & $0.41 \pm 0.03^{*}$ & TRP & $0.26 \pm 0.02^{*}$ \\
DEX & $0.41 \pm 0.12^{*}$ & AN & $0.00 \pm 0.00^{*}$ & TYR & $0.00 \pm 0.00^{*}$ \\
STA & $0.55 \pm 0.12^{*}$ & AS & $0.00 \pm 0.00^{*}$ & VC & $0.01 \pm 0.00^{*}$ \\
GLU & $1.14 \pm 0.14$ & YE & $1.14 \pm 0.14$ & Tween 80 & $1.14 \pm 0.14$ \\
\hline
\end{tabular}

${ }^{a} \mathrm{~N}$, viable cell numbers $(\mathrm{CFU} / \mathrm{ml})$ in each medium; $N_{\mathrm{MRS}}$, viable cell numbers $(\mathrm{CFU} / \mathrm{ml})$ detected in MRS medium.

Data are expressed as the relative fold-change using viable cell numbers (CFU/ml) in MRS medium as the control, and analysis performed by one-way ANOVA.

*Significantly different compared with each control; $p<0.05$.

The concentrations of carbon, nitrogen, and growth factors were $4 \%, 2 \%$, and $0.1 \%$, respectively.

GAL, galactose; FRU, fructose; SUC, sucrose; LAC, lactose; MAL, maltose; DEX, dextrin; STA, soluble starch; GLU, glucose; SP, soy peptone; PP, proteose peptone NO.3; BE, beef extract; TRY, tryptone; CAS, casitone; AN, ammonium nitrate; AS, ammonium sulfate; YE, yeast extract; FA, folic acid; GA, glutamic acid; HIS, histidine; LYS, lysine; TRP, tryptophan; TYR, tyrosine; VC, vitamin C. 
Table 3. Central composite design and responses.

\begin{tabular}{|c|c|c|c|c|c|c|c|}
\hline \multicolumn{6}{|c|}{ Factors and variables } & \multirow{2}{*}{$\begin{array}{c}\text { Response } 1 \\
Y_{1}\end{array}$} & \multirow{2}{*}{$\begin{array}{c}\text { Response } 2 \\
Y_{2}\end{array}$} \\
\hline Run & Block & $X_{1}$ & $X_{2}$ & $X_{3}$ & $X_{4}$ & & \\
\hline 1 & -2 & 3 & 2.5 & 0.05 & 6 & 8.636 & 326.94 \\
\hline 2 & -2 & 4 & 2 & 0.1 & 6.5 & 8.544 & 301.32 \\
\hline 3 & -2 & 3 & 2.5 & 0.15 & 7 & 8.573 & 308.00 \\
\hline 4 & -2 & 5 & 2.5 & 0.05 & 7 & 8.488 & 308.66 \\
\hline 5 & -2 & 5 & 2.5 & 0.15 & 6 & 8.607 & 329.49 \\
\hline 6 & -2 & 3 & 1.5 & 0.05 & 7 & 8.568 & 313.97 \\
\hline 7 & -2 & 5 & 1.5 & 0.15 & 7 & 8.477 & 305.67 \\
\hline 8 & -2 & 4 & 2 & 0.1 & 6.5 & 8.585 & 326.86 \\
\hline 9 & -2 & 3 & 1.5 & 0.15 & 6 & 8.514 & 336.73 \\
\hline 10 & -2 & 5 & 1.5 & 0.05 & 6 & 8.554 & 348.84 \\
\hline 11 & -1 & 3 & 1.5 & 0.15 & 7 & 8.716 & 317.86 \\
\hline 12 & -1 & 3 & 2.5 & 0.15 & 6 & 8.886 & 337.51 \\
\hline 13 & -1 & 3 & 1.5 & 0.05 & 6 & 8.749 & 355.12 \\
\hline 14 & -1 & 3 & 2.5 & 0.05 & 7 & 8.846 & 326.12 \\
\hline 15 & -1 & 5 & 2.5 & 0.15 & 7 & 8.732 & 316.61 \\
\hline 16 & -1 & 5 & 2.5 & 0.05 & 6 & 8.806 & 358.87 \\
\hline 17 & -1 & 5 & 1.5 & 0.05 & 7 & 8.745 & 331.72 \\
\hline 18 & -1 & 4 & 2 & 0.1 & 6.5 & 8.775 & 320.20 \\
\hline 19 & -1 & 4 & 2 & 0.1 & 6.5 & 8.686 & 324.85 \\
\hline 20 & -1 & 5 & 1.5 & 0.15 & 6 & 8.792 & 342.35 \\
\hline 21 & 1 & 4 & 2 & 0 & 6.5 & 8.740 & 454.61 \\
\hline 22 & 1 & 4 & 3 & 0.1 & 6.5 & 8.870 & 313.08 \\
\hline 23 & 1 & 4 & 1 & 0.1 & 6.5 & 8.704 & 330.68 \\
\hline 24 & 1 & 4 & 2 & 0.1 & 6.5 & 8.842 & 319.71 \\
\hline 25 & 1 & 6 & 2 & 0.1 & 6.5 & 8.887 & 309.96 \\
\hline 26 & 1 & 4 & 2 & 0.2 & 6.5 & 8.899 & 328.06 \\
\hline 27 & 1 & 4 & 2 & 0.1 & 7.5 & 8.832 & 325.86 \\
\hline 28 & 1 & 4 & 2 & 0.1 & 5.5 & 8.864 & 376.48 \\
\hline 29 & 1 & 2 & 2 & 0.1 & 6.5 & 8.778 & 325.79 \\
\hline 30 & 1 & 4 & 2 & 0.1 & 6.5 & 8.925 & 319.03 \\
\hline
\end{tabular}

$X_{1}$, Maltose \% (w/v); $X_{2}$, Yeast extract \% $(\mathrm{w} / \mathrm{v}) ; X_{3}$, Tween $80 \%(\mathrm{v} / \mathrm{v}) ; X_{4}$, initial $\mathrm{pH} ; Y_{1}$, viable cell number (log CFU /ml); $Y_{2}$, growth rate (min).

as response surface reduced linear and quadratic models. First, the predicted model for viable cell numbers (log $\mathrm{CFU} / \mathrm{ml}$ ) contained two linear terms as follows:

$$
Y_{1}=8.84053+0.065821 X_{2}-0.038689 X_{4}
$$

where $Y_{1}$ is the predicted response of the bacterial concentration $(\log \mathrm{CFU} / \mathrm{ml})$, and $\mathrm{X}_{2}$ and $\mathrm{X}_{4}$ are the actual values of yeast extract $(\%, \mathrm{w} / \mathrm{v})$ and the initial $\mathrm{pH}$, respectively. The results of ANOVA showed the significance
Table 4. Effects of cryoprotective additives (CPA) candidates on the viability of L. salivarius strain W13 during freeze-drying.

\begin{tabular}{lccc}
\hline \multicolumn{1}{c}{ CPA candidates $^{\mathrm{a}}$} & CFU/g & $\begin{array}{c}\text { Survival } \\
\text { rate }(\%)^{\mathrm{b}}\end{array}$ & $\begin{array}{c}\text { Total dry } \\
\text { weight }(\%)^{\mathrm{c}}\end{array}$ \\
\hline Distilled water (control) & $7.1 \times 10^{6}$ & 0.01 & 1.3 \\
Galactose & $1.2 \times 10^{10}$ & 2.2 & 12.8 \\
Lactose & $1.4 \times 10^{10}$ & 2.6 & 12.1 \\
Maltose & $1.2 \times 10^{10}$ & 2.2 & 12.0 \\
Trehalose & $1.4 \times 10^{10}$ & 2.6 & 8.6 \\
Casitone & $7.3 \times 10^{9}$ & 1.3 & 12.4 \\
Proteose peptone NO. 3 & $7.1 \times 10^{9}$ & 1.2 & 11.1 \\
Yeast extract & $8.5 \times 10^{9}$ & 1.6 & 12.3 \\
Skim milk & $2.2 \times 10^{10}$ & 4.7 & 10.9 \\
Sucrose & $3.7 \times 10^{10}$ & 4.9 & 11.1 \\
SM+SUC & $7.3 \times 10^{10}$ & 11.1 & 11.2 \\
SM+SUC+SG & $2.2 \times 10^{11}$ & 59.5 & 14.2 \\
\hline
\end{tabular}

${ }^{a}$ Each CPA was prepared at a $10 \%$ concentration, except for the SM+SUC and $\mathrm{SM}+\mathrm{SUC}+\mathrm{SG}$ groups.

${ }^{\text {bS }}$ urvival rate $(\%)=\left(\mathrm{CFU}_{\text {dried }} / \mathrm{ml} \div \mathrm{CFU}_{\text {initial }} / \mathrm{ml}\right) \times 100$

${ }^{\mathrm{c}}$ Total dry weight $(\%)=\left(\right.$ weight $_{\text {dried }} \div$ weight $\left._{\text {initial }}\right) \times 100$

SM+SUC, CPA mixture containing 10\% skim milk and $10 \%$ sucrose; SM+SUC+SG, CPA mixture containing $10 \%$ skim milk and $10 \%$ sucrose supplemented with $2.5 \%$ sodium glutamate.

of this model (F-value: $6.43 ; P$-value: $P>F, 0.0056)$. Maltose and Tween 80 did not affect the cell density within the designed variable levels. Even if the $R$-square (0.34) and adjusted $R$-square (0.3) values were too low, the plot of the predicted values versus the actual values of cell number and the plot of externally studentized residuals versus the predicted response with small residuals $(<30 \%)$ demonstrated the significance of this model (Figs. 1A and 1B).

Second, the effect of Tween $80\left(X_{3} ; \%, v / v\right)$ and initial $\mathrm{pH}$ $\left(X_{4}\right)$ on the growth rate $\left(Y_{2}, \mathrm{~min}\right.$.) was predicted, resulting in a quadratic model with two linear and two quadratic terms. The equation was as follows:

$$
\begin{aligned}
& Y_{2}=1583.68588-1556.37779 X_{3}-336.87738 X_{4}+6410.49960 X_{3}^{2} \\
+ & 23.93623 X_{4}^{2}
\end{aligned}
$$

The $F$-value (17.09) and $P$-value $(P>F,<0.0001)$ were determined and indicated the good fit of the model. Despite the low $R$-square (0.75) and adjusted $R$-square (0.70) values, the significance of this model was revealed from the plots of predicted versus actual response and externally studentized residuals versus predicted growth rate $(\mathrm{min})$, with the exception of two runs, nos. 21 and 26 (Figs. 1C and 1D). The reason why the growth rate of run no. 21 was the 
lowest was that the medium did not include any Tween 80 (Table 3).

The optimized parameters within the tested ranges were therefore established as follows: $2.164 \%(\mathrm{w} / \mathrm{v})$ of maltose, $3 \%(\mathrm{w} / \mathrm{v})$ of yeast extract, $0.121 \%(\mathrm{v} / \mathrm{v})$ of Tween 80 , and an initial $\mathrm{pH}$ value of 6.646, demonstrating desirability (0.7), with a growth prediction of $8.78 \mathrm{log} \mathrm{CFU} / \mathrm{ml}$ and a 307.57 growth rate ( $\mathrm{min}$ ) (Fig. S1). Maltose had no effect on the optimized results. The conditions described above were designated as RSM medium (Table S2). Additionally, post analysis of the optimized conditions was carried out, and both of the predicted responses $\left(Y_{1}\right.$ and $\left.Y_{2}\right)$ belonged within the range of the prediction intervals (between 95\% low and high). The reproducibility of the optimized model was therefore confirmed.

In the RSM medium, it was confirmed that yeast extract could potentially be used at concentrations greater than $3 \%$ $(\mathrm{w} / \mathrm{v})$ for increasing viable cell numbers. Therefore, we modified the concentration of yeast extract from $2 \%$ to $9.5 \%$ $(\mathrm{w} / \mathrm{v})$ in the RSM medium, and inoculated strain W13 at $1 \%(\mathrm{w} / \mathrm{v})$. Bacterial growth was less than $1.0 \times 10^{9} \mathrm{CFU} / \mathrm{ml}$ with yeast extract in the range of $2-4.5 \%(\mathrm{w} / \mathrm{v})$, whereas
A

A

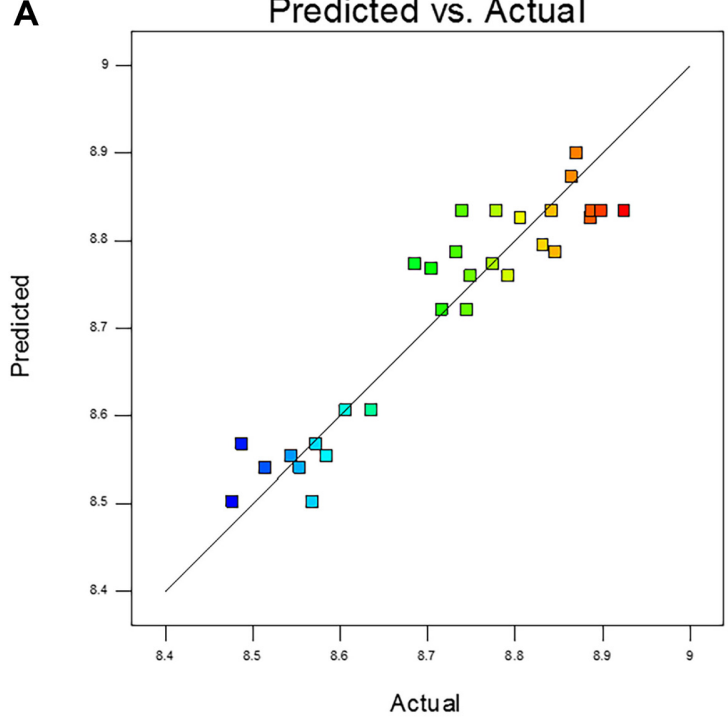

C

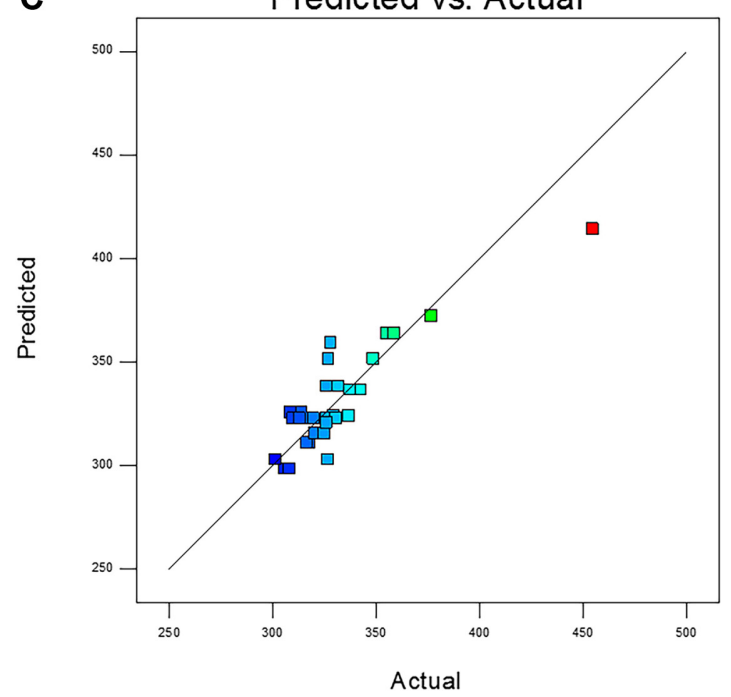

B

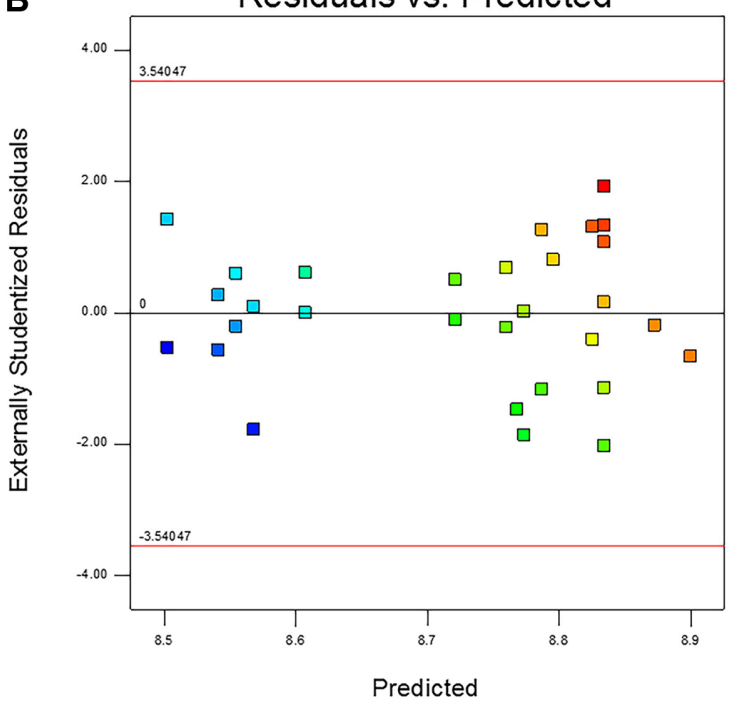

D

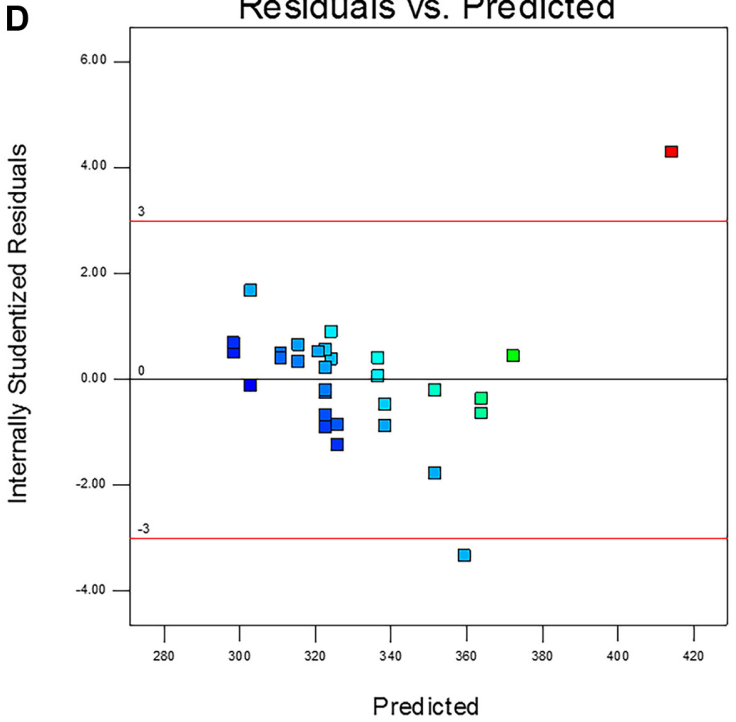

Fig. 1. Plot of predicted versus actual values and the studentized residuals versus predicted values of the viable cell counts (A, B) and growth rates $(\mathbf{C}, \mathbf{D})$, respectively. 


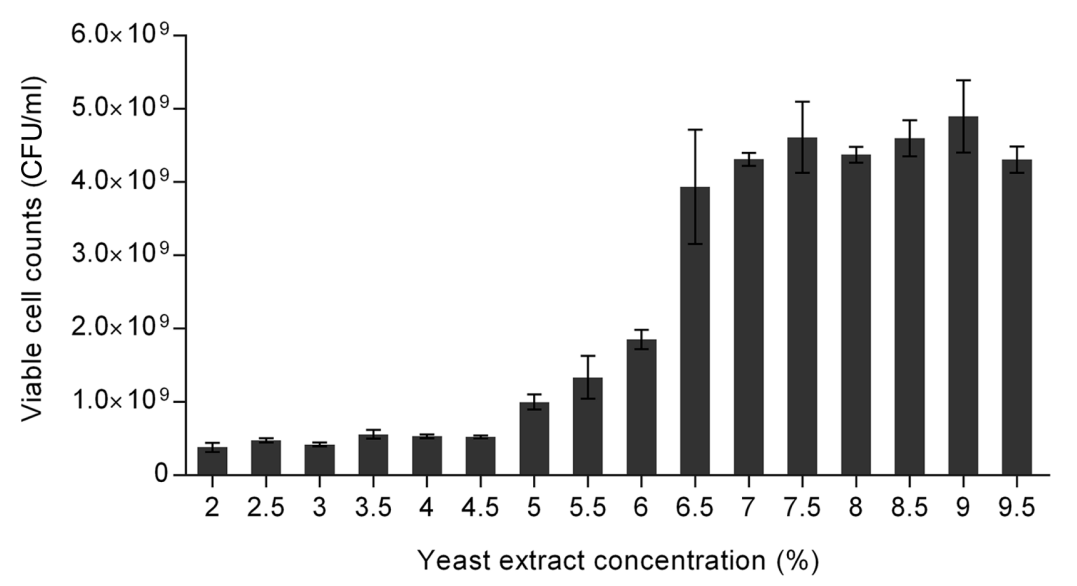

Fig. 2. Effects of different concentrations of yeast extract $(2-9.5 \%, \mathrm{w} / \mathrm{v})$ on cell counts of L. salivarius strain W13 at the stationary phase.

cell growth improved up to $5.0 \times 10^{9} \mathrm{CFU} / \mathrm{ml}$ above $7.5 \%$ $(\mathrm{w} / \mathrm{v})$ yeast extract concentration (Fig. 2). The RSM medium was therefore modified to contain a yeast extract concentration of $8.5 \%(\mathrm{w} / \mathrm{v})$ for subsequent studies, and this modified medium was designated LDTM in this study (Table S2).

Availability of LDTM medium. The viable cell number of $L$. salivarius strain W13 grown in LDTM medium was compared with cell counts in MRS and RSM media. The cell populations in LDTM medium were $4.6 \times 10^{9}$ and $2.0 \times$ $10^{9} \mathrm{CFU} / \mathrm{ml}$ in cultures of laboratory $(50 \mathrm{ml})$ and fermenter

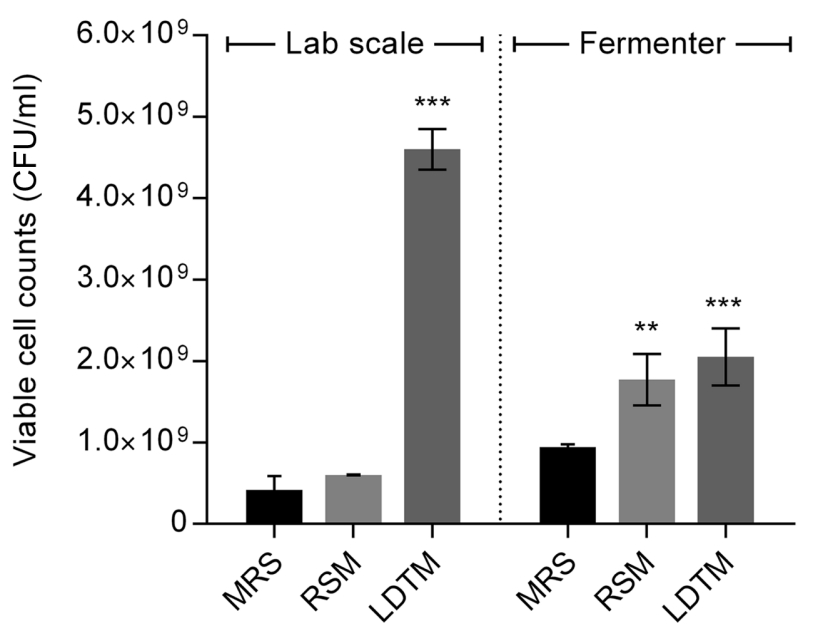

Fig. 3. Comparison of viable cell numbers $(\mathrm{CFU} / \mathrm{ml})$ of L. salivarius strain W13 cultured in LDTM medium with MRS and RSM media in laboratory and fermenter systems.

The data represent the means and standard errors of more than three replicates. Significance is indicated as follows: ${ }^{* *} P \leq 0.01$; ${ }^{* * *} P \leq 0.001$.
(5-L) scale, respectively. These cell counts corresponded to significant 11- and 2.2-fold increases compared with the cell counts in MRS medium for each scale of culture (Fig. 3). The applicability of the LDTM conditions for improving the growth of other species was investigated using 12 strains, consisting of seven L. salivarius strains and five commercial probiotics of other Lactobacillus spp. Strains of the species $L$. salivarius showed significantly higher growth in fermenter-scale LDTM medium, with an increase of approximately 1.9-7.8-fold, compared with laboratory-scale MRS medium. By contrast, the growth of strains of other Lactobacillus species in fermenters of LDTM medium was decreased or did not differ significantly from the growth observed in 50-ml flasks of MRS medium (Fig. 4).

\section{Determination and Validation of Cryoprotective Additives}

Selection of CPA candidates. The bacterial cells that were suspended in skim milk and sucrose showed the highest viability, corresponding to survival rates of $4.7 \%$ $\left(2.2 \times 10^{10} \mathrm{CFU} / \mathrm{g}\right)$ and $4.9 \%\left(3.7 \times 10^{10} \mathrm{CFU} / \mathrm{g}\right)$, respectively, and were thus selected as individual growth factors (Table 4). Except for skim milk and sucrose, mono- and disaccharides showed higher cryoprotective effects than nitrogen complex compounds. The combinations of skim milk and sucrose enhanced the viable cell numbers (CFU/g) and survival rates (\%) to $7.3 \times 10^{10} \mathrm{CFU} / \mathrm{g}$ and $11.1 \%$, respectively. Moreover, the addition of sodium glutamate increased the viability 3.0-fold compared with the mixture of the two factors alone, enabling the viability of the culture to reach $2.2 \times 10^{11} \mathrm{CFU} / \mathrm{g}$.

The influence of cryoprotectants was verified on the basis of quantification of live and dead cells among the 


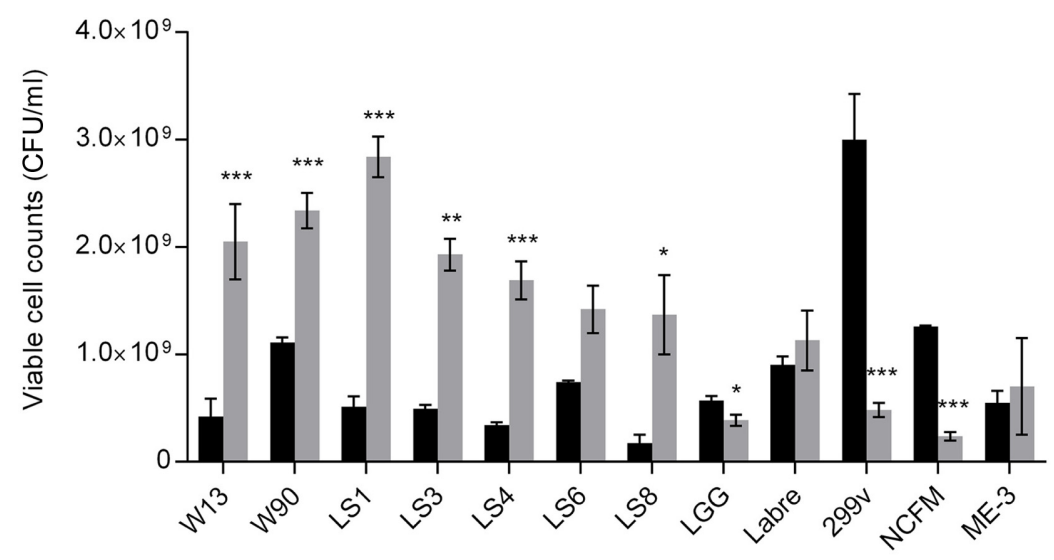

Fig. 4. Bacterial viable cell numbers (CFU/ml) cultivated in MRS medium in 50-ml flasks (black) and LDTM medium in 5-L fermenters (grey).

See also Table S1 for information on the microorganisms tested. W13, W90, LS1, LS3, LS4, LS6, and LS8: L. salivarius strains; LGG: L. rhamnosus GG (ATCC 53103); Labre: L. brevis subsp. coagulans Labre; 299v: L. plantarum 299v; NCFM: L. acidophilus NCFM; ME-3: L. fermentum ME-3. Significance is indicated as follows: ${ }^{*} P \leq 0.05 ; * * P \leq 0.01 ; * * P \leq 0.001$.

freeze-dried cells using flow cytometry and fluorescence microscopy (Fig. 5). Prior to the validation, the correlation between the flow cytometer count (bacteria/ml) and the plate count (CFU/ml) was evaluated (Fig. S2). The sole use of skim milk led to the lowest ratio of live cells at $37 \%$, whereas addition of sodium glutamate to the mixture of skim milk and sucrose resulted in a 9:1 live to dead cell ratio after freeze-drying (Fig. 5A). Similar results were obtained by fluorescence microscopy observations (Figs. 5B and $5 \mathrm{C}$ ). Thus, the mixture of these three chemicals was finally selected and then tested on other Lactobacillus strains.

Availability of the selected CPA mixture. The selected CPA combination affected the viability of 12 lactobacilli strains with strain-specific features (Fig. 6A). Among the L. salivarius strains tested, strains W13 and LS6 contained more than $90 \%$ of viable cells, as compared with less than $61 \%$ live cells for the other L. salivarius strains. The CPA mixture significantly protected the viable cells of Lactobacillus brevis subsp. coagulans strain Labre $(96.9 \%$ of live cells in the freeze-dried cells), but did not exert this protective effect on Lactobacillus acidophilus strain NCFM, which showed a 1:4 live to dead cell ratio.

The ATP activity (S:N) of freeze-dried cells was also measured to detect metabolically active cells (Fig. 6B). The relative correlation between the $\mathrm{S}: \mathrm{N}$ ratio and the number of viable cells ( $\mathrm{CFU} / \mathrm{g}$ ) in the immediate recovery status after freeze-drying was defined by the following equation ( $R$-square 0.87 ):

$$
\mathrm{S}: \mathrm{N}=8.36 \times 10^{-8} \times(\mathrm{CFU} / \mathrm{g})-5.219
$$

with the exception of L. fermentum ME-3 and L. brevis subsp. coagulans Labre. Even though strain ME-3 showed a relatively similar S:N value to $L$. salivarius strain LS1, the viable cell number was about 4.6-times different. The recovered cell count $(\mathrm{CFU} / \mathrm{g})$ was the highest in strain Labre, but its S:N value was low (286). Because the ATP activity (S:N) of L. salivarius strain W13 was too high, it is not included in Fig. 6B.

\section{Discussion}

The LAB comprise a heterogeneous group of grampositive, catalase-negative, nonsporulating rods or cocci, producing lactate as a major end-product of carbohydrate metabolism [28]. Based on their functional properties, some LAB can be considered as probiotics, which are defined as "a live microorganism that, when administered in adequate amounts, confers a health benefit on the host" (FAO/WHO) [29]. The sources of ingested probiotic LAB have been widened in recent years from simply consuming unknown microbial complexes in fermented foods to ingesting a specific strain or multiple strains in the form of tablets or capsules as dietary supplements $[8,30,31]$. These changes have been led by technological developments in the large-scale cultivation and lyophilization of LAB, thereby enabling long-term storage of these products. The current research aimed to develop an optimal growth medium and investigate appropriate CPAs for L. salivarius, one of the promising probiotic LAB species, and then evaluate the effectiveness of the determined conditions on 

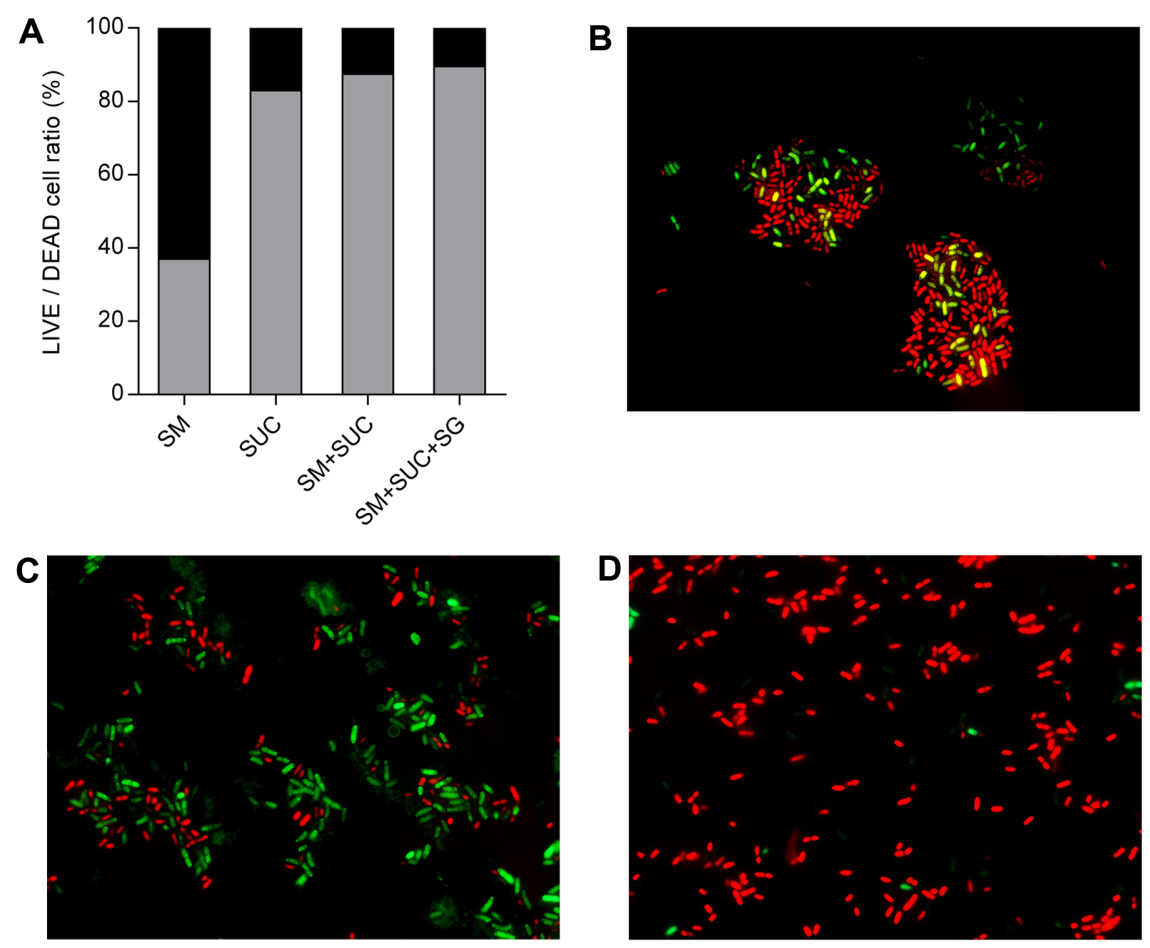

Fig. 5. Visual verification of the effects of cryoprotective additives (CPAs) on the viability of L. salivarius strain W13.

(A) Effects of CPAs on the bacterial live (grey) to dead (black) cell ratio. SM, 10\% (w/v) skim milk; SUC, 10\% (w/v) sucrose; SM+SUC, 10\% (w/v) skim milk and 10\% (w/v) sucrose; SM+SUC+SG, 10\% (w/v) skim milk and 10\% (w/v) sucrose supplemented with $2.5 \%$ (w/v) sodium glutamate. Fluorescence microscopy images of strain W13 after freeze-drying using CPAs of (B) 10\% (w/v) skim milk, (C) 10\% (w/v) skim milk and 10\% (w/v) sucrose supplemented with $2.5 \%(\mathrm{w} / \mathrm{v})$ sodium glutamate, and (D) distilled water as a negative control. The staining with fluorescent markers represents bacterial live cells (green) and dead cells (red).

the growth of other lactobacilli.

The nutrient requirements of lactobacilli are complex and either strain- or species-dependent in the fermentation of carbohydrates, nitrogen sources, fatty acids, and growth
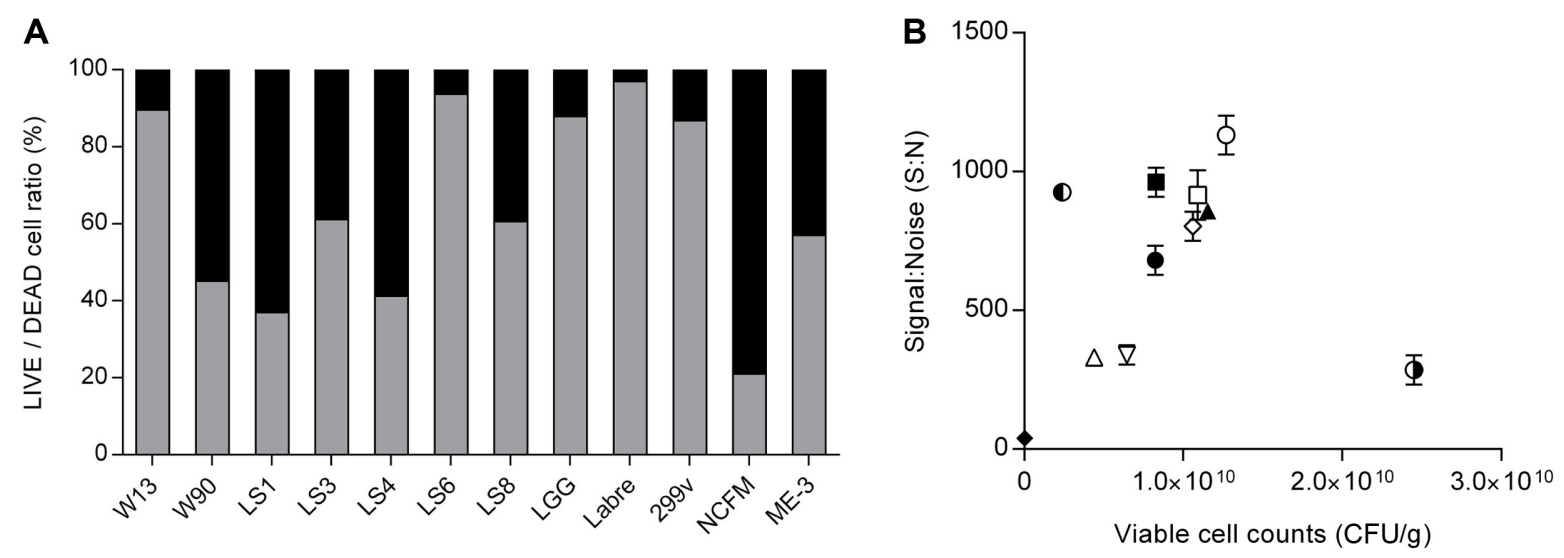

Fig. 6. Effects of the optimized cryoprotective additive mixture on various Lactobacillus strains.

(A) Effect of the determined CPA mixture on the bacterial live (grey) to dead (black) cell ratio. (B) Correlation between bacterial cell number (CFU/g) and the ATP values (S:N) of freeze-dried cells. The symbols indicate the following species and strains: L. salivarius strains ( $\bullet$, W90; $\square$, LS1; $\mathbf{\square}$, LS3; $\triangle$, LS4; $\mathbf{\Delta , ~ L S 6 ; ~} \nabla$, LS8), L. rhamnosus (LGG, O), L. brevis subsp. coagulans (Labre, (), L. plantarum (299V, $\diamond)$, L. acidophilus (NCFM, ४), L. fermentum (ME-3, D). L. salivarius strain W13 was not included in panel (B). 
factors $[2,32]$. Among the nutrients tested in this study, maltose, yeast extract, and Tween 80 were selected for improving the growth of L. salivarius strains (Table 2). Yeast extract significantly improved the viable cell numbers of L. salivarius strain W13, particularly at concentrations above $6.5 \%(\mathrm{w} / \mathrm{v})$ (Fig. 2). According to Hammes and Hertel [32], obligate homofermentative $\mathrm{LAB}$, including the species L. salivarius, cannot produce certain essential molecules for growth, such as purine and pyrimidine bases and ribose 5-phosphate. For that reason, L. salivarius is highly dependent on organic nitrogen sources (e.g., yeast extract, tryptone, and peptones), rather than inorganic nitrogen sources (e.g., ammonium nitrate and ammonium sulfate). This was supported by our results, as shown in Table 2. Yeast extract is widely used for the cultivation of lactobacilli because it is an abundant source of nitrogen, the vitamin B group, purine, and pyrimidine [33]. Amrane and Prigent [34] reported that the yeast extract concentration (ranging between 20 and $30 \mathrm{~g} / \mathrm{l}$ ) enhanced the biomass production and growth rate during homolactic fermentation of L. helveticus [34]. Similarly, the effects of yeast extract on growth have been reported in other species, such as L. rhamnosus [15, 21], L. acidophilus [35], and L. salivarius [18, 36]. Despite efforts to find a suitable partial or total replacement for yeast extract owing to its high cost [37-40], it has proven difficult to replace its effectiveness in the cultivation of lactobacilli $[18,41]$. The identification of an appropriate yeast extract substitute for $L$. salivarius cultivation will be the subject of ongoing studies.

Maltose is a disaccharide composed of two D-glucose residues joined by an $\alpha(1 \rightarrow 4)$ glycosidic linkage. Mokhtari et al. [42] reported that some Lactobacillus species, including L. salivarius, L. fermentum, and L. reuteri, utilize MalY protein for maltose uptake and MalP protein for phosphorolysis of maltose to glucose and glucose-1-phosphate, which are converted into glucose-6-phosphate for glycolysis. Although maltose was selected as an individual carbon source for L. salivarius cultivation (Table 2), this nutrient had no impact on optimization in the central composite design model. In addition, when maltose at concentrations ranging from 10 to $60 \mathrm{~g} / 1$ was applied to RSM medium, no significant effect on the cell density of strain W13 was observed (data not shown). Thus, it is postulated that strain W13 prefers to utilize maltose metabolism, regardless of the quantity of maltose.

Tween 80 (a polyethylene sorbitol ester) contains fatty acids comprising $70 \%$ oleic acid. Because of its surfactant function leading to increased permeability, Tween 80 has been frequently used for the mass production of intracellular compounds, such as lactic acid in L. delbrueckii strain NCIM 2025 [43] and the enzyme $\beta$-glucosidase in L.fermentum strain CM33 [44]. Regarding bacterial growth, oleic acid can be incorporated into bacterial membranes and can then promote the transportation of nutrients and exterior protons into cells, resulting in an enhanced bacterial growth rate [45]. Furthermore, a correlation between Tween 80 and the initial $\mathrm{pH}$ of the medium during bacterial cultivation was reported $[45,46]$. As shown in our central composite design model (Fig. S3 and Table 3), both Tween 80 and the initial $\mathrm{pH}$ affected the growth rate $\left(\mathrm{Y}_{2}\right)$, and the response was more sensitive to Tween 80 than the initial $\mathrm{pH}$ in perturbation analysis (Fig. S3B). This result indicates that Tween 80 is suitable for lactobacilli cultivation as an essential growth factor with an appropriately neutral initial $\mathrm{pH}$ for inclusion in MRS medium [13].

Our optimized LDTM medium was found to be more applicable to laboratory-scale culture than fermenter-scale culture (Fig. 3). For large-scale production, the cultivation conditions in the fermenter require further optimization, which will be the subject of a future study. Nevertheless, the cell number of strain W13 increased 2.2-fold in LDTM medium compared with MRS medium in the fermenter (Fig. 3). As shown in Fig. 4, the microbial nutrient requirements differ between Lactobacillus species and strains, and LDTM medium was found to be adequate to improve the growth of L. salivarius strains, but not other Lactobacillus species. We therefore suggest that LDTM medium has the potential to be used for the large-scale production of L. salivarius strains.

Freeze-drying is widely used for long-term storage of LAB. Microorganisms are exposed to stress via a variety of processes, such as freezing, dehydration, and high pressure. These stressful environments lead to a reduction in viability, stability, and metabolic activity. According to Carvalho et al. [47], several factors may affect the survival of LAB, including intrinsic features, cultivation medium [48, 49], pretreatment of sublethal cold shock [50,51], CPAs [20, 52, 53], and rehydration [54]. Among these factors, the effect of CPAs on bacterial viability was investigated after freezedrying in this study. The CPA mixture of skim milk $(10 \%$, $\mathrm{w} / \mathrm{v})$, sucrose $(10 \%, \mathrm{w} / \mathrm{v})$, and sodium glutamate (final $2.5 \%, \mathrm{w} / \mathrm{v}$ ) was determined to be an effective supplement for the survival of L. salivarius strain W13 (Table 4 and Fig. 5). Milk proteins such as skim milk have been widely employed as CPAs for microorganisms because they build layers around the cell walls that offer protection from ice and allow for $\mathrm{pH}$ stabilization by adjusting the levels of solutes such as calcium [20,47]. Moreover, sucrose, which 
is also classified as a non-penetrating CPA, not only allows for stabilization, but also prevents protein denaturation by interacting with proteins and membranes [55]. It is known that combinations of cryoprotectants are usually more effective than individual CPAs as they show synergic effects [56]. For example, sodium glutamate was more effective when used with other CPAs in Lactobacillus, Streptococcus, and Leuconostoc species [57, 58]. In this study, supplementation with $2.5 \%(\mathrm{w} / \mathrm{v})$ sodium glutamate showed synergic effects, resulting in significantly enhanced viability (up to $59.5 \%$ survival rate) of strain W13 after freeze-drying (Table 4). It is worth noting that the Tween 80 in LDTM medium might increase tolerance to stress and contribute towards protecting cells during freeze-drying by altering the fatty acid composition in the cell membrane [58-60].

Based on the definition of microbial viability by Kell et al. [61], microbial status can be classified as "viable and active", "viable but inactive" (dormant), "nonviable and active", and dead. The viability of lyophilized LAB has been mostly quantified by culture-dependent methods by measuring colony-forming units (CFUs). However, the counts obtained mainly represent "viable and active" cells, not dormant (ultimately cultivable) or dead cells. Moreover, there is a limitation during recovery that the culture conditions of the agar plate are directly related to viability, and thereby, this may affect the formation of colonies in some LAB species [62]. Therefore, culture-independent methods have been recently proposed for precise quantification of probiotic LAB after lyophilization using alternative techniques, such as imaging with fluorescence [63, 64], nucleic acid detection by qRT-PCR [23, 65], and cell sorting using flow cytometry $[22,23]$. Among these techniques, we adopted dual-staining fluorescence-based assays for the evaluation of CPA effects on microbial viability by discriminating between viable (live; active or inactive) and non-viable (dead; active or dead) cells (Figs. 5 and 6A). Furthermore, the metabolically active status was also evaluated by detecting ATP during the recovery of freeze-dried cells. To our best knowledge, this is the first study to apply the ATP method for studying the effect of CPAs on the viability of LAB. In this study, the cryoprotective effects of the selected CPA mixture differed among Lactobacillus strains (Fig. 6A). It might be that the specific preferences of particular strains for intrinsic factors and growth medium ingredients lead to differences in the live/dead ratios after lyophilization [47, 56]. In addition, the metabolic activity of the recovered microbial cells correlated with viable cell numbers (CFU/g) for most of the species and strains tested, with the exception of
L. fermentum ME-3 and L. brevis subsp. coagulans Labre (Fig. 6B). These exceptional traits should be considered as intrinsic features related to the recovery and replication abilities of each strain. Therefore, the identification of appropriate CPA candidates needs to be carried out in a targeted strain-specific manner. For example, in the case of L. brevis subsp. coagulans Labre, factors for the rapid restoration of metabolic activity after rehydration should be investigated if necessary.

The results of this study demonstrate that (i) nutrient requirements tend to be species-dependent; therefore, we suggest that our LDTM medium could be applied to improve the growth of L. salivarius species; and (ii) enhancement of microbial viability during freeze-drying should be considered by employing CPAs as well as other relevant factors. Therefore, our findings highlight the fact that investigations for cryoprotective conditions need to be conducted in a targeted strain-specific manner. Furthermore, culture-independent techniques enable more precise and advanced evaluation for bacterial viable state in the lyophilized product, and may support the large-scale production of probiotics in the food, feed, and pharmaceutical industries.

\section{Acknowledgments}

We are grateful for the kind support of Prof. Marika Mikelsaar, University of Tartu, in providing L. fermentum strain ME-3 for this research. This study was supported by a grant from the Strategic Initiative for Microbiomes in Agriculture and Food, Ministry of Agriculture, Food and Rural Affairs (MAFRA), Republic of Korea, as part of the Post Genome Joint Department Genome Project (Grant ID: 914005-04). We thank Dr. Kate Fox from Edanz Group (http://www.edanzediting.com/ac) for editing a draft of this manuscript.

\section{Conflict of Interest}

The authors have no financial conflicts of interest to declare.

\section{References}

1. Ljungh A, Wadström T. 2006. Lactic acid bacteria as probiotics. Curr. Issues Intest. Microbiol. 7: 73-89.

2. Holzapfel WH, Wood BJB. 2014. Introduction to the LAB, pp. 1-12. In Holzapfel WH, Wood BJB (eds.), Lactic Acid Bacteria - Biodiversity and Taxonomy. John Wiley \& Sons Ltd., 
Chichester, West Sussex, UK.

3. Serban DE. 2014. Gastrointestinal cancers: influence of gut microbiota, probiotics and prebiotics. Cancer Lett. 345: 258-270.

4. Dahiya DK, Renuka, Puniya M, Shandilya UK, Dhewa T, Kumar N, et al. 2017. Gut microbiota modulation and its relationship with obesity using prebiotic fibers and probiotics: a review. Front. Microbiol. 8: 563.

5. Sánchez B, Delgado S, Blanco-Míguez A, Lourenço A, Gueimonde M, Margolles A. 2017. Probiotics, gut microbiota, and their influence on host health and disease. Mol. Nutr. Food Res. 61: 1600240.

6. Marchesi JR, Adams DH, Fava F, Hermes GD, Hirschfield GM, Hold G, et al. 2016. The gut microbiota and host health: a new clinical frontier. Gut 65: 330-339.

7. van den Elsen LW, Poyntz HC, Weyrich LS, Young W, Forbes-Blom EE. 2017. Embracing the gut microbiota: the new frontier for inflammatory and infectious diseases. Clin. Transl. Immunol. 6: e125.

8. Grand View Research, Inc. 2017. Probiotics dietary supplements market analysis by application (food supplements, nutritional supplements, specialty nutrients, infant formula), by regions (north America, Europe, Asia Pacific, Middle East \& Africa, CSA), and segment forecasts, 2014-2025. Report ID: GVR-168038-380-5.

9. Feighery LM, Smith P, O'Mahony L, Fallon PG, Brayden DJ. 2008. Effects of Lactobacillus salivarius 433118 on intestinal inflammation, immunity status and in vitro colon function in two mouse models of inflammatory bowel disease. Dig. Dis. Sci. 53: 2495-2506.

10. Messaoudi S, Manai M, Kergourlay G, Prévost H, Connil N, Chobert JM, et al. 2013. Lactobacillus salivarius: bacteriocin and probiotic activity. Food Microbiol. 36: 296-304.

11. Murphy EF, Cotter PD, Hogan A, O'Sullivan O, Joyce A, Fouhy F, et al. 2013. Divergent metabolic outcomes arising from targeted manipulation of the gut microbiota in dietinduced obesity. Gut 62: 220-226.

12. Jin GD, Lee JY, Kim EB. 2017. Draft genome sequence of Lactobacillus salivarius KLW001 isolated from a weaning piglet. Korean J. Microbiol. 53: 134-136.

13. de Man JD, Rogosa M, Sharpe ME. 1960. A medium for the cultivation of lactobacilli. J. Appl. Bacteriol. 23: 130-135.

14. Hwang CF, Chang JH, Houng JY, Tsai CC, Lin CK, Tsen HY. 2012. Optimization of medium composition for improving biomass production of Lactobacillus plantarum Pi06 using the Taguchi array design and the Box-Behnken method. Biotechnol. Bioprocess Eng. 17: 827-834.

15. Liew SL, Ariff AB, Raha AR, Ho YW. 2005. Optimization of medium composition for the production of a probiotic microorganism, Lactobacillus rhamnosus, using response surface methodology. Int. J. Food Microbiol. 102: 137-142.

16. Tari C, Ustok FI, Harsa S. 2009. Optimization of the associative growth of novel yoghurt cultures in the production of biomass, $\beta$-galactosidase and lactic acid using response surface methodology. Int. Dairy J. 19: 236-243.

17. Lew LC, Liong MT, Gan CY. 2013. Growth optimization of Lactobacillus rhamnosus FTDC 8313 and the production of putative dermal bioactives in the presence of manganese and magnesium ions. J. Appl. Microbiol. 114: 526-535.

18. Dong Z, Gu L, Zhang J, Wang M, Du G, Chen J, et al. 2014. Optimisation for high cell density cultivation of Lactobacillus salivarius BBE 09-18 with response surface methodology. Int. Dairy J. 34: 230-236.

19. Fahy GM, Wowk B. 2015. Principles of cryopreservation by vitrification. In Wolkers WF, Oldenhof $\mathrm{H}$ (eds.), Cryopreservation and freeze-drying protocols. Methods Mol. Biol. 1257: 21-82.

20. Ming LC, Rahim RA, Wan HY, Ariff AB. 2009. Formulation of protective agents for improvement of Lactobacillus salivarius I 24 survival rate subjected to freeze drying for production of live cells in powderized form. Food Bioprocess Technol. 2: 431-436.

21. Siaterlis A, Deepika G, Charalampopoulos D. 2009. Effect of culture medium and cryoprotectants on the growth and survival of probiotic lactobacilli during freeze drying. Lett. Appl. Microbiol. 48: 295-301.

22. Rault A, Béal C, Ghorbal S, Ogier JC, Bouix M. 2007. Multiparametric flow cytometry allows rapid assessment and comparison of lactic acid bacteria viability after freezing and during frozen storage. Cryobiology 55: 35-43.

23. Kramer M, Obermajer N, Bogovic Matijasić B, Rogelj I, Kmetec V. 2009. Quantification of live and dead probiotic bacteria in lyophilised product by real-time PCR and by flow cytometry. Appl. Microbiol. Biotechnol. 84: 1137-1147.

24. Berney M, Hammes F, Bosshard F, Weilenmann HU, Egli T. 2007. Assessment and interpretation of bacterial viability by using the LIVE/DEAD BacLight Kit in combination with flow cytometry. Appl. Environ. Microbiol. 73: 3283-3290.

25. Pascaud A, Amellal S, Soulas ML, Soulas G. 2009. A fluorescence-based assay for measuring the viable cell concentration of mixed microbial communities in soil. $J$. Microbiol. Methods 76: 81-87.

26. Frey DD, Wang H. 2006. Adaptive one-factor-at-a-time experimentation and expected value of improvement. Technometrics 48: 418-431.

27. Yeo S, Park H, Ji Y, Park S, Yang J, Lee J, et al. 2015. Influence of gastrointestinal stress on autoinducer-2 activity of two Lactobacillus species. FEMS Microbiol. Ecol. 91: fiv065.

28. Pfeiler EA, Klaenhammer TR. 2007. The genomics of lactic acid bacteria. Trends Microbiol. 15: 546-553.

29. Food and Agriculture Organization of the United Nations/ World Health Organization (FAO/WHO). 2001. Report of the Joint $\mathrm{FAO} / \mathrm{WHO}$ expert consultation on evaluation of health and nutritional properties of probiotics in food including powder milk with live lactic acid bacteria, 1-4 October 2001, Córdoba, Argentina. FAO, Rome, Italy.

30. Holzapfel W, Olasupo N, Haberer P. 1998. Lactobacilli in a healthy diet, pp. 20-32. In Gaukel V, Spieb WEL (eds.), 
Proceedings (Part 1) of the 3rd Karlsruhe Nutrition Symposium: European Research Towards Safer and Better Food.

31. Markets and Markets Analysis. 2013. Probiotics market by products (functional foods, dietary supplements, specialty nutrients, animal feed), applications (regular, therapeutic, preventive health care) \& ingredients (lactobacilli, bifidobacteria, yeast) - global trends \& forecasts to 2017. Available at http:// www.marketsandmarkets.com/.

32. Hammes WP, Hertel C. 2006. The genera Lactobacillus and Carnobacterium. Prokaryotes 4: 320-403.

33. Aeschlimann A, von Stockar U. 1990. The effect of yeast extract supplementation on the production of lactic acid from whey permeate by Lactobacillus helveticus. Appl. Microbiol. Biotechnol. 32: 398-402.

34. Amrane A, Prigent Y. 1998. Influence of yeast extract concentration on batch cultures of Lactobacillus helveticus: growth and production coupling. World J. Microbiol. Biotechnol. 14: 529-534.

35. Champagne CP, Gaudreau H, Conway J, Chartier N, Fonchy E. 1999. Evaluation of yeast extracts as growth media supplements for lactococci and lactobacilli by using automated spectrophotometry. J. Gen. Appl. Microbiol. 45: 17-21.

36. Lim CH, Rahim RA, Ho YW, Arbakariya BA. 2007. Optimization of growth medium for efficient cultivation of Lactobacillus salivarius I 24 using response surface method. Malays. J. Microbiol. 3: 41-47.

37. Arasaratnam V, Senthuran A, Balasubramaniam K. 1996. Supplementation of whey with glucose and different nitrogen sources for lactic acid production by Lactobacillus delbrueckii. Enzyme Microb. Technol. 19: 482-486.

38. Yoo IK, Chang HN, Lee EG, Chang YK, Moon SH. 1997. Effect of $\mathrm{B}$ vitamin supplementation on lactic acid production by Lactobacillus casei. J. Ferment. Bioeng. 84: 172-175.

39. Nancib N, Nancib A, Boudjelal A, Benslimane C, Blanchard F, Boudrant J. 2001. The effect of supplementation by different nitrogen sources on the production of lactic acid from date juice by Lactobacillus casei subsp. rhamnosus. Bioresour. Technol. 78: 149-153.

40. Liu B, Yang M, Qi B, Chen X, Su Z, Wan Y. 2010. Optimizing L-(+)-lactic acid production by thermophile Lactobacillus plantarum As.1.3 using alternative nitrogen sources with response surface method. Biochem. Eng. J. 52: 212-219.

41. Gao X, Qiao SY, Lu WQ. 2009. Determination of an economical medium for growth of Lactobacillus fermentum using response surface methodology. Lett. Appl. Microbiol. 49: 556-561.

42. Mokhtari A, Blancato VS, Repizo GD, Henry C, Pikis A, Bourand A, et al. 2013. Enterococcus faecalis utilizes maltose by connecting two incompatible metabolic routes via a novel maltose-6'-phosphate phosphatase (MapP). Mol. Microbiol. 88: 234-253.

43. Srivastava AK, Tripathi AD, Jha A, Poonia A, Sharma N. 2015. Production, optimization and characterization of lactic acid by Lactobacillus delbrueckii NCIM 2025 from utilizing agro-industrial byproduct (cane molasses). J. Food Sci. Technol. 52: 3571-3578.

44. Sriphannam W, Unban K, Ashida H, Yamamoto K, Khanongnuch C. 2012. Medium component improvement for $\beta$-galactosidase production by a probiotic strain Lactobacillus fermentum CM33. Afr. J. Biotechnol. 11: 11242-11251.

45. Jacques NA, Hardy L, Knox KW, Wicken AJ. 1980. Effect of Tween 80 on the morphology and physiology of Lactobacillus salivarius strain IV CL-37 grown in a chemostat under glucose limitation. J. Gen. Microbiol. 119: 195-201.

46. Corcoran BM, Stanton C, Fitzgerald GF, Ross RP. 2007. Growth of probiotic lactobacilli in the presence of oleic acid enhances subsequent survival in gastric juice. Microbiology 153: 291-299.

47. Carvalho AS, Silva J, Ho P, Teixeira P, Malcata FX, Gibbs P. 2004. Relevant factors for the preparation of freeze-dried lactic acid bacteria. Int. Dairy J. 14: 835-847.

48. Carvalho AS, Silva J, Ho P, Teixeira P, Malcata FX, Gibbs P. 2003. Effect of various growth media upon survival during storage of freeze-dried Enterococcus faecalis and Enterococcus durans. J. Appl. Microbiol. 94: 947-952.

49. Chen H, Chen S, Chen H, Wu Y, Shu G. 2014. Effects of carbon sources and prebiotics added to growth media on proliferation and survival of Lactobacillus bulgaricus LB6 during freeze-drying. J. Chem. Pharm. Res. 6: 894-899.

50. van de Guchte $M$, Serror P, Chervaux C, Smokvina $T$, Ehrlich SD, Maguin E. 2002. Stress responses in lactic acid bacteria. Antonie Van Leeuwenhoek 82: 187-216.

51. Reddy KBPK, Awasthi SP, Madhu AN, Prapulla SG. 2009. Role of cryoprotectants on the viability and functional properties of probiotic lactic acid bacteria during freeze drying. Food Biotechnol. 23: 243-265.

52. Juárez Tomás MS, Bru E, Martos G, Nader-Macías ME. 2009. Stability of freeze-dried vaginal Lactobacillus strains in the presence of different lyoprotectors. Can. J. Microbiol. 55: 544-552.

53. Li B, Tian F, Liu X, Zhao J, Zhang H, Chen W. 2011. Effects of cryoprotectants on viability of Lactobacillus reuteri CICC6226. Appl. Microbiol. Biotechnol. 92: 609-616.

54. Zhao G, Zhang G. 2005. Effect of protective agents, freezing temperature, rehydration media on viability of malolactic bacteria subjected to freeze-drying. J. Appl. Microbiol. 99: 333-338.

55. Crowe JH, Crowe LM, Carpenter JF, Rudolph AS, Wistrom CA, Spargo BJ, Anchordoguy TJ. 1988. Interactions of sugars with membranes. Biochim. Biophys. Acta 947: 367-384.

56. Hubálek Z. 2003. Protectants used in the cryopreservation of microorganisms. Cryobiology 46: 205-229.

57. Morichi T, Irie R, Yano N, Kembo H. 1963. Protective effect of glutamic acid and related compounds on bacterial cells subjected to freeze-drying. J. Gen. Appl. Microbiol. 9: 149-161.

58. Coulibaly I, Dubois-Dauphin R, Destain J, Fauconnier ML, Lognay G, Thonart P. 2010. The resistance to freeze-drying 
and to storage was determined as the cellular ability to recover its survival rate and acidification activity. Int. J. Microbiol. 625239: 1-9.

59. Gilliland SE, Speck ML. 1974. Frozen concentrated cultures of lactic starter bacteria. A review. J. Milk Food Technol. 37: 107-111.

60. Smittle RB, Gilliland SE, Speck ML, Walter WM Jr. 1974. Relationship of cellular fatty acid composition to survival of Lactobacillus bulgaricus in liquid nitrogen. Appl. Microbiol. 27: 738-743.

61. Kell DB, Kaprelyants AS, Weichart DH, Harwood CR, Barer MR. 1998. Viability and activity in readily culturable bacteria: a review and discussion of the practical issues. Antonie Van Leeuwenhoek 73: 169-187.

62. Davis C. 2014. Enumeration of probiotic strains: review of culture-dependent and alternative techniques to quantify viable bacteria. J. Microbiol. Methods 103: 9-17.

63. Yao AA, Dortu C, Egounlety M, Pinto C, Edward VA, Huch M, et al. 2009. Production of freeze-dried lactic acid bacteria starter culture for cassava fermentation into gari. Afr. J. Biotechnol. 8: 4996-5004.

64. Lee SB, Kim DH, Park HD. 2016. Effects of protectant and rehydration conditions on the survival rate and malolactic fermentation efficiency of freeze-dried Lactobacillus plantarum JH287. Appl. Microbiol. Biotechnol. 100: 7853-7863.

65. Radulović Z, Mirković N, Bogovič-Matijašić B, Petrušić M, Petrović T, Manojlović V, et al. 2012. Quantification of viable spray-dried potential probiotic lactobacilli using real-time PCR. Arch. Biol. Sci. 64: 1465-1472. 